\title{
Microporous sol-gel membranes for molecular separations
}

\section{Ann. Chim. Sci. Mat., 2007, 32(2), pp 231-244}

\author{
J.F. Vente
}

H.M. van Veen

P.P.A.C. Pex

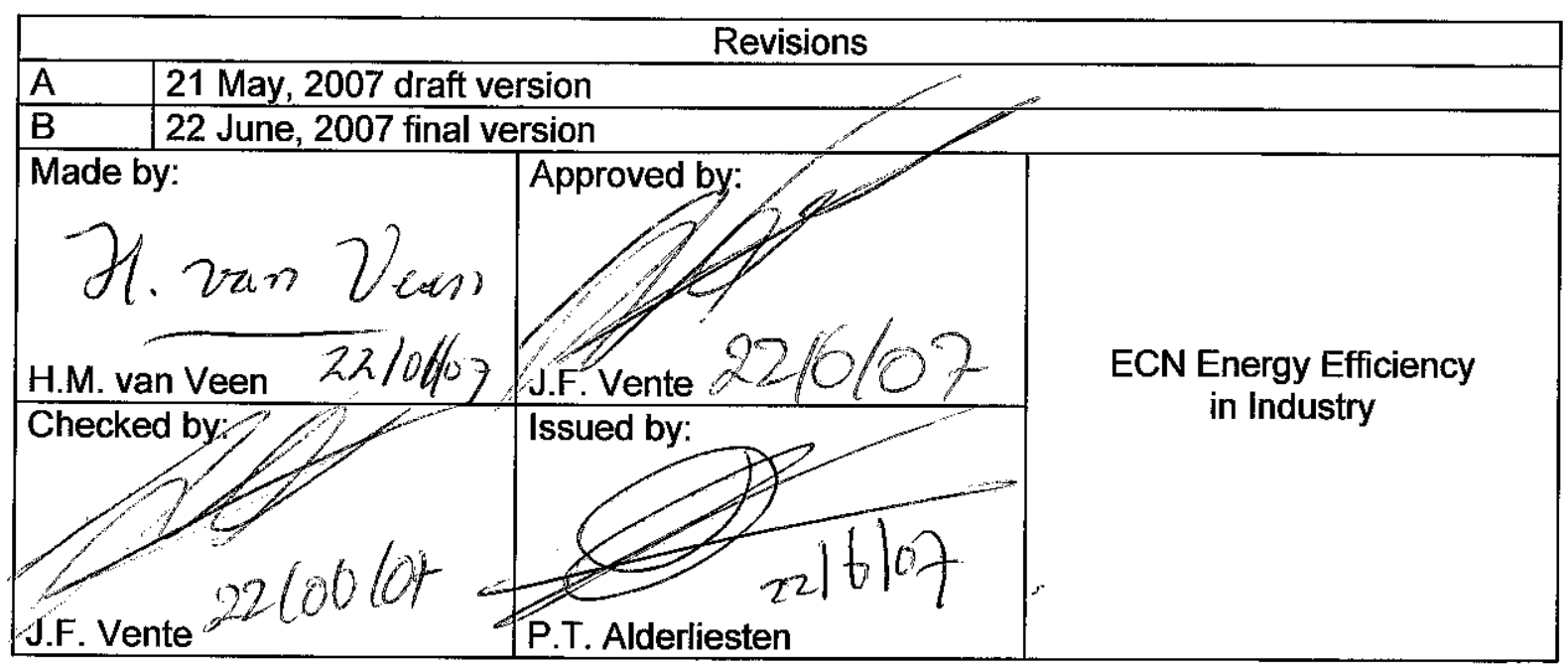

JUNE 2007 


\begin{abstract}
Molecular separations are very important in many production processes and they account for considerable energy consumption. Microporous membranes are a very efficient alternative to the very energy-intensive and widely-used distillation. Sol-gel membranes offer many opportunities in this respect because of the wide variety of materials and pore structures that can be made. The cost of such membranes is generally dominated by the cost of the support structure that must be of very high quality due to the hierarchical nature of the asymmetrical membrane system (a hole in the support will give a defect in the membrane). The selectivity is very strongly depending on pore characteristics and defect status and thus controlling the manufacturing parameters is essential for reproducible production. Employing proper characterisation techniques in a prudent way is important for effective membrane development and eventual efficient membrane production. Next to the issue of reproducible membrane production on large scale there remains the issue of membrane stability and sufficient long-term performance in industrial applications. As sol-gel membranes have an amorphous structure and a very high specific surface area there is a significant driving force to transform into a structure with a lower energy state. Active operation of sol-gel membranes seems to accelerate this transformation and the challenge is to reduce the kinetics of this process to obtain membranes with sufficient life-time for industrial applications.
\end{abstract}




\section{Contents}

List of tables $\quad 4$

List of figures $\quad 4$

1. Introduction 5

2. Analysis methods $\quad 7$

3. Supports 9

4. Materials for microporous sol-gel membranes 10

5. Large scale testing and economics 13

6. Concluding remarks 18

References $\quad 19$ 


\section{List of tables}

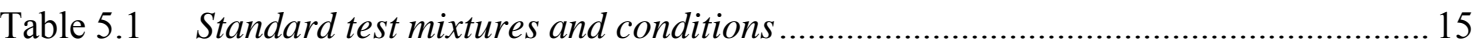

\section{List of figures}

Figure 1.1 Generic process scheme highlighting different separation steps......

Figure 2.1 Visual identification of defects with a dye (left) and investigation of their origin with FESEM (right)

Figure 4.1 Impression of the coating process (left) and of the sol preparation route (right) .. 10

Figure 4.2 Permporometry graph of titania and zirconia membranes compared with that of methylated silica

Figure 5.1 Methanol and water concentration in permeate for all membrane batches in the period 1999-2005 (left) and performance of membrane batches made on commercial supports only (right)

Figure 5.2 Methanol or water conc. in the permeate vs. $\mathrm{MeOH}$ or $\mathrm{H}_{2} \mathrm{O}$ flux ......................... 14

Figure 5.3 Pilot scale $1 \mathrm{~m}^{2}$ membrane area pervaporation test system .................................. 15

Figure 5.4 Pilot scale test results with $0.9 \mathrm{~m}^{2} \mathrm{PV}$ membrane test system at $95^{\circ} \mathrm{C}$ : left, fluxes and $\mathrm{MeOH}$ concentration in permeate vs. feed, and right, decrease of the

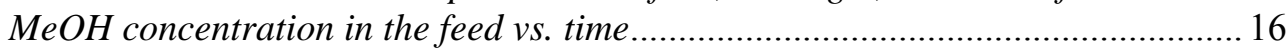

Figure 5.5 Schematic presentation of existing $\mathrm{MeOH}$-toluene process .................................... 16

Figure 5.6 Influence of feed concentration on $\mathrm{MeOH}$ and 100'toluene flux and permeate purity for MeOH-toluene

Figure 5.7 Cost comparison of conventional extraction/distillation process vs. pervaporation 


\section{Introduction}

Molecular separation processes for the recovery and purification of the final products account for over $40 \%$ of the energy consumption in the industry. The generic process scheme as shown in Figure 1.1 can be applied to a wide range of production processes in sectors like food, metallurgy, and the (petro)chemistry. In this scheme the following separation processes can be distinguished:

- the removal of impurities from raw materials (A),

- the separation of products from by-products originating from the reactor crude (B),

- the removal of contaminants from water (C) and air effluents (D).

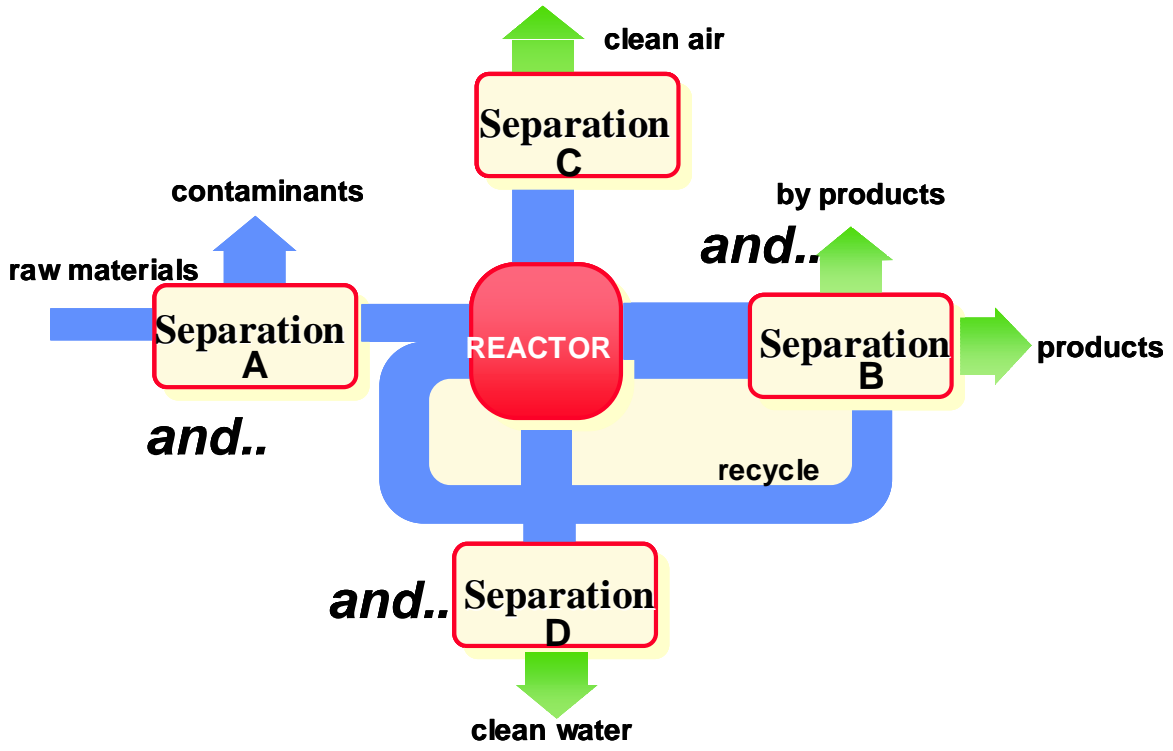

Figure 1.1 Generic process scheme highlighting different separation steps

Typical techniques to perform these separation processes include absorption, adsorption, ion exchange, chromatography, crystallization, distillation, drying, electrodialysis, electrolytic processes, evaporation, extraction, filtration, flotation, membranes and stripping. Thermodynamic calculations [1] show that membranes for molecular separations are one of the most energy-efficient unit operations especially when operated in Separations A and B in the generic process scheme. Separation $\mathrm{C}$ and $\mathrm{D}$ are also very important with respect to environmental issues, i.e. pollution; the energy consumption, however, is negligible. For the membranes to perform Separations A and B a number of different materials has been proposed, such as organic polymers [2] and crystalline and amorphous microporous inorganic materials [3]. The selectivity (separation performance) of dense polymeric membranes is determined by the quotient of the product of solubility (S) and diffusivity (D) of each of the constituents in a mixture. If $S \cdot D$ is significantly higher for one of the constituents compared to the others then such membrane might be industrially interesting depending on process conditions. Polymeric membranes are relatively easy to make in sheet form or as hollow fibre. Their main drawback is their constrained operating window with respect to pressure and especially temperature and their low resistance to organic-containing process feeds. Inorganic microporous membranes, i.e. with pores smaller than $2 \mathrm{~nm}$, have in this respect a much wider applicability but they are more difficult to manufacture. Microporous membranes can be applied for those separations where either the size of molecules or the specific interaction of one of the molecules to be separated with porous material of the membrane delivers the desired selectivity. If the selectivity is sufficient, the important issues for a membrane process to become economically feasible are the permeance (flux), the lifetime, and the capital investment costs. 
Crystalline microporous materials, such as zeolite crystals, shaped into a thin defect-free multicrystalline layer would be a perfect membrane with only one pore diameter. A large amount of research $[4,5]$ has been conducted to achieve such an ideal membrane system. Difficulties in obtaining sufficient control over the crystal growing process, at especially industrial-sized membrane areas, have prevented the large scale implementation to date. Still, Mitsui BNRI is currently very actively commercializing zeolite A membranes for the dehydration of bio-ethanol [5]. Sol-gel processing offers a very interesting technology to achieve microporous membranes. By hydrolysis and subsequent condensation reactions metal precursors can be transformed into small particles which are dispersed in a solvent (the so-called sol). These particles form the basic building blocks in the layer application (gelation) process to manufacture the membrane. The possibility of varying the precursors, sol synthesis parameters and gelation conditions gives numerous degrees of freedom to manufacture tailor-made membranes. As for the zeolite membranes, the challenge is to manufacture large surface areas of an extremely thin membrane layer (up to $100 \mathrm{~nm}$ ) in the desired geometry. In this paper, an overview is given of the current state-of-the-art of microporous sol-gel membranes for molecular separations. Topics to be discussed include materials aspects, manufacturing issues, and application opportunities. To have a sound understanding of this a short overview of analysis methods is given. 


\section{Analysis methods}

Dedicated and sophisticated analysis methods need to be employed to both assess the basic applicability of the microporous membranes and to monitor the influence of processing parameters in the manufacturing of the membranes. Here the analysis methods that are most basic and relevant to microporous sol-gel membranes are discussed.

\section{Gas physisorption}

The pore size and pore size distribution of the microporous membranes are of prime importance and can be determined by gas physisorption. Nitrogen physisorption is generally used in porous materials characterization such as catalysts and gives information on the pore characteristics and specific (Brunauer, Emmett, and Teller, BET) surface area. This technique is also frequently employed in the characterization of sol-gel membrane materials. As a sol-gel membrane layer on top of a porous support is only about $100 \mathrm{~nm}$ thick the amount of membrane material to be characterized is generally too small to see any response in the adsorption curve. To overcome this problem sample preparation is done by pouring some millilitres of the sol in a watch glass followed by the same heat treatment as the membrane (sol-gel layer on a porous support). This way, the selective membrane material is available as flakes for characterization. One of the drawbacks of this technique is that the smallest micropores are not accessible for nitrogen as the molecular diameter of nitrogen is too large and such a characterization becomes inaccurate or even invaluable. Further, the pore size distribution of the thin membrane layer is likely to be different from that of the flake, as the drying rate is an influential parameter in the final pore structure. So gas physisorption of flake material, even with very small molecules such as carbon dioxide, water, or acetylene, might not give a proper indication of the pore structure of the actual membrane.

\section{Permporometry}

Permporometry does not have the problems and drawbacks as described above, and is especially well-suited for the determination of the intrinsic pore size distribution of a supported membrane layer. In permporometry the dried microporous membrane is at first fed with a non-adsorbing non-condensing gas with the smallest diameter possible, e.g. $\mathrm{He}$ or $\mathrm{H}_{2}$. This gives the basic permeance through the membrane. Then an increasing amount of a vapour is added causing an increasing blocking of the pores (the smallest first). Consequently, the permeance of the noncondensable gas decreases with increasing relative vapour pressure of the condensable gas. As water is a very small molecule it is very well suited to probe even the smallest pores. Close to a relative vapour pressure of one, the permeance of the permanent gas should be zero. Any remaining permeance can be ascribed to the presence of macro-defects in the membrane. In this way, a perfect measure of the defect state of the membrane is obtained. A qualitative indication of the pore size distribution can be obtained by recalculating the relative vapour pressure to a length scale by using the Kelvin equation:

$$
d_{k}=-4 \nu_{m} / R T \ln \left(\frac{p}{p_{0}}\right)
$$

where $d_{k}$ is the Kelvin pore diameter, $\gamma$ the surface tension, $v_{m}$ the molar volume, $R$ the gas constant, $\mathrm{T}$ the temperature, $\mathrm{p}$ the (partial)vapour pressure and $\mathrm{p}_{0}$ the saturated vapour pressure. However, one should realise that the Kelvin equation is not valid at these small pore sizes. This technique is described in more detail by e.g. Tsuru [6] and Deckman [7]. For membranes with larger pore diameters other condensable gases can be used such as hexane.

\section{Bubble number curves}

An excellent manner to quantify the largest defects in a membrane structure is a bubble number point measurement. This method is similar to finding a leak in a tire by immersing it in water 
and putting air pressure in it. In this case a membrane is immersed in a wetting liquid (e.g. water, ethanol or isopropanol) and an increasing gas or air pressure is put on the other side. Thus the bubble point (largest defect) and bubble number curve is obtained indicating the quality of the membrane in terms of non-selective leaks. The size of the leaks can be calculated with the Laplace equation:

$$
d_{l}=\frac{4 \gamma}{\Delta P} \cos \theta,
$$

where $d_{1}$ is the Laplace pore diameter, $\Delta \mathrm{P}$ the pressure difference over the membrane and $\theta$ the contact angle. A more thorough description of this technique has been written by Bonekamp [8].

\section{Scanning Electron Microscopy}

For investigating the thickness and structure of the membrane a Field Emission Scanning Electron Microscope (FESEM) is very important. At high magnification the structure of the membrane layers can be examined whereas at lower magnification the defects and their possible origin can be examined. One should realize that the defects have a size in the order of 1-2 micrometer at distances of several centimeters from each other. This means that it takes several tens of minutes of searching before finding such very detrimental defects. A very effective way of approach is to first identify the detrimental defects visually with a dye, followed by a targeted sample preparation for studying the origin of the defects, see Figure 2.1.

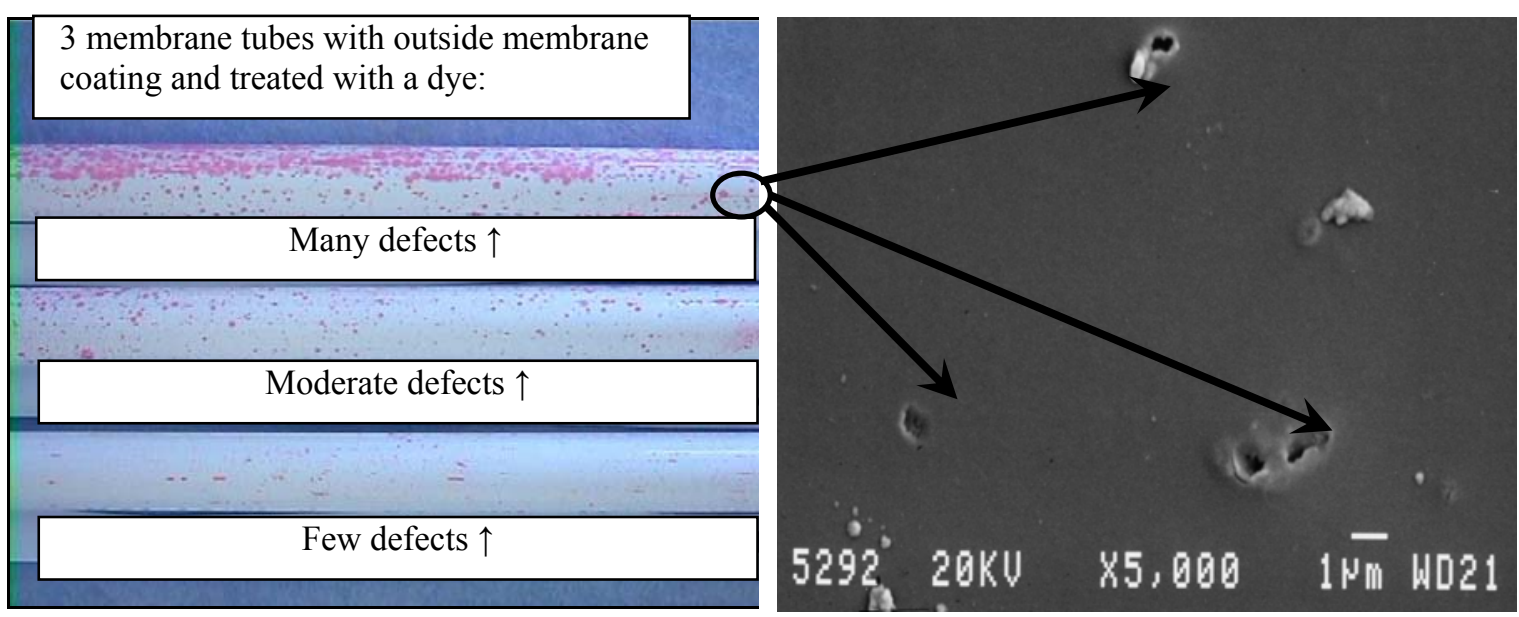

Figure 2.1 Visual identification of defects with a dye (left) and investigation of their origin with FESEM (right)

\section{Permeative characterizations}

Single gas permeation measurements using gases with different molecule sizes on a thoroughly dried membrane give an indication of the intrinsic pore structure and the possible performance of the membrane in the anticipated application. In such test a specific (adsorbing) interaction with the pore wall material of the probe gas should be taken into account. Carbon dioxide is well known for this. Ultimately, gas separation testing with gas mixtures or pervaporation with liquid mixtures gives information on the anticipated industrial performance of the membrane. Although this performance is principally determined by the membrane material characteristics, many other aspects of process technology nature can play a very dominant role. In situations of concentration polarization (significant depletion of permeating component at the feed side), temperature polarization (temperature drop by evaporation of permeating component and thus reduction of driving force) or competitive adsorption in multi-component feeds, these techniques can hardly be used to investigate the influence of processing parameters on eventual membrane pore structure. However, given a reproducible membrane manufacturing procedure, these separation techniques are absolutely essential for application and process technology research. 


\section{Supports}

Microporous sol-gel membrane layers are too thin $(100 \mathrm{~nm})$ to be used as a free standing material, and the selective layer must be applied to porous support structures to give the membrane structural rigidity. Support structures with different geometries can be used such as tubes, hollow fibres, multi-channels or planar type. The optimal geometry is depending mainly on the hydrodynamic process conditions. The main requirements to the support systems are the pore and defect structure as well as production costs. The importance of the support structure to the overall membrane performance is well appreciated by the ceramic membrane community. The amount of research performed on this topic is still limited. The effective membrane layer constitutes only a minor part of the total membrane system, and the cost of the membrane is mainly determined by the support cost. As a result, inorganic membranes are more expensive per unit surface area, than polymeric membranes. This higher price is, however, more than compensated by a higher permeance and longevity. Furthermore it should be kept in mind that the membranes are only a small part of the total price of a complete membrane system. The high permeance of the microporous sol-gel membranes puts a strict demand on the pore structure of the support system. The flux resistance of the support should account for less than $10 \%$ of the total membrane resistance. This is especially the case in pervaporation applications where the feed is a liquid and the permeate is a vapour. The tremendous volume expansion from the feed side to the permeate side requires a very open support structure. Sol-gel membrane layers are usually $\sim 100 \mathrm{~nm}$ thick. In the case of perfect layers, the pore characteristics, such as pore size distribution, tortuosity and connectivity, are the determining factors for the separation performance. This performance is further influenced by the physical and chemical properties of the solid-fluid interfaces. The selectivity decreases when channels are present that are much larger than the intrinsic pore size. These so-called defect pores are formed during the dipcoating process, due to asperities, larger voids, and dust particles, or during the drying/consolidating stage, due to shrinkage and interaction with the substrate. It is obvious that the concentration of imperfections must be kept as low as possible. One of the requirements to obtain such a layer is a support structure that is smooth, flawless and homogeneous. Much research in the sol-gel membrane field has been done by using gamma alumina support tubes available from commercial membrane producers who sell them as microfiltration membranes. And indeed these membranes are very good in ultrafiltration operation which is a liquid based, more-or-less particle filtration process with a filter cake layer that predominantly acts as the membrane. However, because of the stacking of membrane layers in asymmetric membrane systems, the largest defects in underlying layers will always continue in the next finer layer. The most commonly used gamma alumina membrane as substrate has a mean pore size of $4 \mathrm{~nm}$ but in this system still pores of 0.2 to 0.4 micrometer are present [8]. Such support is not good enough for a sol-gel membrane layer for molecular separations. Good controlled processing with de-agglomerated and well-dispersed, stable suspensions can deliver improved quality supports. Furthermore, it has been shown that making an intermediate layer by coating several identical thin layers on top of each other instead of coating a thick layer in one step gives a significant improvement in the defect quality of such intermediate layer and thus of the total membrane system. It has been shown that the optimal result of bulk characteristics in thin layers can be obtained with such an approach [8]. Considering the cost aspect of multiple coatings it should be considered that an intelligent optimum should be found in this. Although it is recognized in the membrane literature that defects in supports do play an important role in (reproducible) membrane performances no quantitative information in this respect is available in the open literature. 


\section{Materials for microporous sol-gel membranes}

In the eighties of the previous century the early pioneers in sol-gel processing were Jeffrey Brinker in the United States and Jacques Livage in France. The book "Sol-Gel Science" authored by Brinker and Scherer [9] is currently one of the most frequently cited references in this field. Based on this work, the groups of Prof. Burggraaf at the University of Twente, The Netherlands, and Prof. Cot at the University of Montpellier, France, started to employ sol-gel chemistry in their membrane research. The membranes were mainly tested in gas separation applications because of their significantly larger selectivity for e.g. hydrogen separation from methane than mesoporous membranes, which are limited to selectivities based on Knudsen diffusion. In principle sol-gel chemistry can be employed according to two routes. The first route is based on the formation of colloids in aqueous media in which the stability of dispersions is controlled by the attractive and repulsive forces between the colloids. The second route is based on the reaction (mostly hydrolysis) of metal-organic precursors in organic media. The molecular species thus formed can be considered as inorganic polymers and are small enough to remain separated in the solution (see also Figure 4.1 (right). This second route gives building blocks that are small enough to give microporous materials by the gelation process and that can be used as molecular separation membrane. For this purpose the sol is coated on e.g. a tubular support, as described above, as shown in Figure 4.1 (left). In the gelation process the organic dispersant is evaporated while concurrently polymerisation of the inorganic polymers takes place. Many parameters such as original sol species, drying speed and acid/catalyst concentration determine the characteristics of the obtained microporous structure and thus the separation capabilities the membrane layer. The majority of the work has been done on the silica system because of the moderate reactivity of the precursors. Based on silicon a very diverse variety of precursors is currently available giving the possibility of very creative sol-gel chemistry.
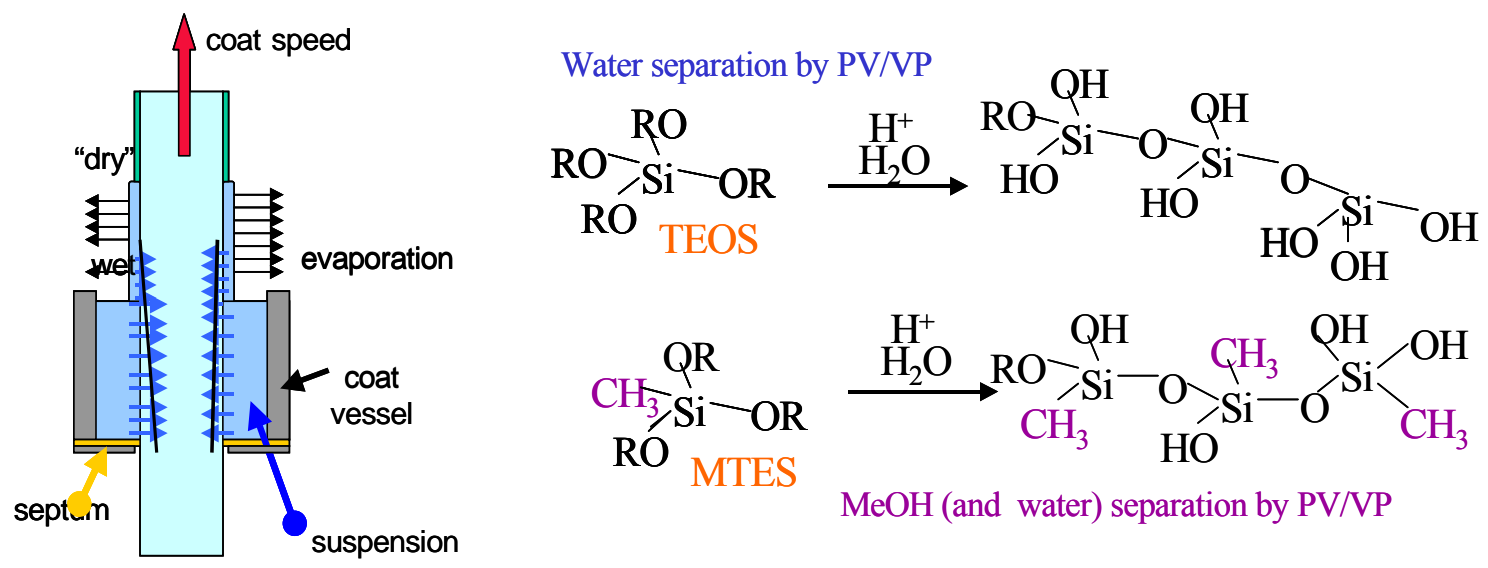

Figure 4.1 Impression of the coating process (left) and of the sol preparation route (right)

Also a great variety of templating strategies employing ligands, molecules and supramolecular assemblies have been developed to precisely control the characteristics of porous films that can be used as membranes. The precursors of other interesting membrane materials such as zirconia and titania have a reactivity of orders of magnitude higher than silica which makes it very difficult to use them in controlled hydrolysis for making sols for microporous membranes. The expected high chemical and thermal stability of inorganic membranes compared to polymer membranes has resulted in a growing research activity with the aim of replacing polymer membranes with inorganic ones. The superior separation performance, i.e. selectivity and flux, of silica-based membranes in the dehydration of alcohols and solvents at elevated temperatures 
has raised the interest even further. High flux performance is required especially to overcome the higher unit cost price of the inorganic membranes. The required water flux of at least $3 \mathrm{~kg} / \mathrm{m}^{2} \cdot \mathrm{h}$, for the dehydration of $5 \mathrm{wt} . \%$ water in butanol as a representative standard application, can be achieved easily [10]. The development of highly selective pure silica membranes was pioneered by De Vos [11] about ten years ago. The use of a clean room to prevent the incorporation of dust particles into the selective top layer was shown to be crucial. However, the profitable application of inorganic membranes depends also on a reliable, stable long-term behaviour. Unfortunately, information on this topic is still very limited. Dehydration experiments (pervaporation) at temperatures below $100^{\circ} \mathrm{C}$ indicate a fast decrease of the water flux through silica membranes during the first few days of operation [10]. The origin of this decline has not been determined yet, but we believe that sorption processes on the membrane surface play an important role. Further the maximum temperature for the usage of pure silica in dehydration applications is limited to approximately $70^{\circ} \mathrm{C}[10,12]$. Both the flux decline as well as maximum operating temperature can be improved by incorporating methyl groups in the silica structure as proposed by De Vos [13]. The water flux decline of the methylated silica $\left(\mathrm{Me}-\mathrm{SiO}_{2}\right.$ ) during the first weeks is limited to $\sim 20 \%$ and is stable hereafter at $95^{\circ} \mathrm{C}$. Dehydration experiments performed up to $165^{\circ} \mathrm{C}$ using these $\mathrm{Me}-\mathrm{SiO}_{2}$ membranes showed membrane failure after 4 to 40 days due to reorganization of the silica structure [10]. In all cases a strong increase in the organic flux was observed in pervaporation. This was taken as an indication that the pore size increased over time. The application window of state-of-the-art $\mathrm{Me}^{-\mathrm{SiO}_{2}}$ membranes for use in dehydration processes is limited to $95^{\circ} \mathrm{C}$.

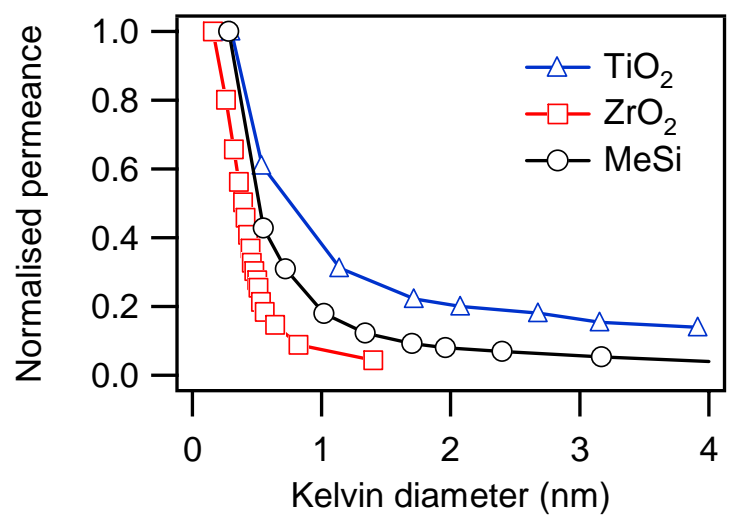

Figure 4.2 Permporometry graph of titania and zirconia membranes compared with that of methylated silica

Several strategies have been tried and tested to improve the hydrothermal stability of the amorphous silica membranes. The first option is to employ metal oxides with more stable M-O bonds such as $\mathrm{TiO}_{2}$ and $\mathrm{ZrO}_{2}$. The much higher hydrolysis and condensation rates result in a hard to control sol-gel process. Still, some results of making these microporous membranes have been published. Puhlfürß [14] reports an amorphous microporous $\mathrm{TiO}_{2}$ membrane system with cut-off of $380 \mathrm{Da}$, and a mean pore diameter of $0.9 \mathrm{~nm}$. These characteristics make this membrane very suitable for nanofiltration and salt retention applications. The pores are however too large to perform an effective molecular separation. These results were later reproduced by other laboratories [15-17]. The amount of information on $\mathrm{ZrO}_{2}$ membranes is even more limited. Van Gestel [18] prepared some membranes with a very promising cut-off value in nanofiltration. Further, the room temperature chemical stability against acids and bases appears to be very high. The permeance is very low though. At the Energy research Centre of the Netherlands, we have succeeded to prepare pure titania and zirconia membranes with a mean Kelvin diameter of about $5-7 \AA$ (Figure 4.2). This graph shows that the intrinsic pores are somewhat larger than those of methylated silica prepared according to the De Vos recipe [13]. The first indications are that these membranes can selectively remove water from a wide range of organic solvents in pervaporation but that the flux decreases very rapidly. Further, the reproducibility of the membrane preparation process is very low at this moment, due to 
difficulties in controlling all steps in the sol-gel process. Apart from the difficult sol-gel procedures, the amorphous microporous $\mathrm{TiO}_{2}$ and $\mathrm{ZrO}_{2}$ membranes tend to crystallize relatively easily. The crystallization temperature in air is reported to lie in the range of $300-400^{\circ} \mathrm{C}$ $[16,18,19]$. However, in the presence of water this is reduced to about $80^{\circ} \mathrm{C}$ [20]. Attempts to increase the crystallization temperatures by mixing $\mathrm{TiO}_{2}$ and $\mathrm{ZrO}_{2}$ precursors have been very successful [19]. Still, if a mixed metal precursor is being employed the transition temperature can be even further enhanced to about $750^{\circ} \mathrm{C}$ [21]. The effect on the hydrothermal crystallization temperature has not been disclosed as yet. Apart from preparing titania-zirconia mixed metal oxide membranes, also silica-based mixed metal membranes have been proposed. Asaeda added zirconia [22-24] and various transition metals [25]. In this way the relatively low reaction rates of the silica precursors and the low tendency to crystallize of the amorphous silica network are combined with the increased chemical stability of zirconia. A different strategy is to alter the silica network without replacing the silicon. The hydrothermal degradation of silica membranes can be ascribed to the net reaction $\equiv \mathrm{Si}-\mathrm{O}-\mathrm{Si} \equiv+\mathrm{H}_{2} \mathrm{O} \rightarrow 2 \equiv \mathrm{Si}-\mathrm{OH}$. As a result silica moieties from high energy sites near nanopores are displaced to lower energy sites elsewhere in the material where the density is higher. A recent development has been to replace the Si-O-Si bonds by hydrolytically stable $\mathrm{Si}-\mathrm{CH}_{2}-\mathrm{CH}_{2}-\mathrm{Si}$ links [26]. The concept has resulted in a microporous membrane that can be used under hydrothermal pervaporation conditions up to at least $150^{\circ} \mathrm{C}$ for over 18 months. A full paper on this concept will soon be published elsewhere [26]. A third strategy is to stabilize the porous network by introducing carbon fragments inside the pores as proposed by Duke et al. [27,28]. The idea is that the internal pore structure cannot be reorganized because of the presence of inert carbon nanoparticles inside the pores. The effect of the carbon nanoparticles is a reduced hydrolysis of the internal surface of the microporous silica network and a reduced mobility of the hydrolysed silica species. More details about this strategy can be found in references [27,28]. 


\section{Large scale testing and economics}

A pure silica membrane is selective for water vs. organics but can hardly separate $\mathrm{MeOH}$ or EtOH from organics as the pore size is too small. Methyl groups were incorporated in the silica structure to improve the hydrothermal stability of the silica material (see Chapter 4). If methyl groups are incorporated into the silica structure and the membrane preparation method has been altered, the pore size increases slightly and the membrane becomes capable of separating methanol from organics. This membrane is still capable of separating water from organics with nearly the same selectivity as the pure silica membrane [10,12,29-34]. However, the hydrothermal stability in dehydration applications of a methylated silica membrane is much higher than the pure silica membrane [10]. In this chapter we report on our observations in the process of up scaling the methylated silica membranes, their first industrial process testing in the separation of methanol (MeOH) from methyltertbutylether (MTBE), and the economics of a process in which $\mathrm{MeOH}$ needs to be separated from toluene with these membranes.

\section{Membrane reproducibility}

At the start of the development work at ECN, the methylated silica membranes were applied on ECN's 'homemade' high-quality substrate tubes with well-defined pore sizes. Following this, in order to reduce costs and to scale up the membrane production easily to commercial area sizes, the recipes have been optimized for coating commercial low-cost substrate tubes that are abundantly available. The performance of the membranes using the commercial low-cost supports in pervaporation is good and comparable with the 'homemade' supported membranes. We have tested the membranes in standard pervaporation tests in which two feeds containing either A.) 5 wt. $\%$ of methanol in MTBE at $45^{\circ} \mathrm{C}$ or B.) 5 wt. $\%$ water in butanol at $95^{\circ} \mathrm{C}$ are separated over the membrane. In Figure 5.1 (left) the results of the methanol and the water permeate concentration are given for all membrane batches made during a 5 year period: 1999 till 2005. The results in Figure 5.1 (left) show a large variation in the methanol concentration in the permeate and therefore in the membrane selectivity. At first sight this is not in line with the relative small variation in dehydration behaviour of the same membrane pieces, indicated by the solid squares in Figure 5.1 (left).
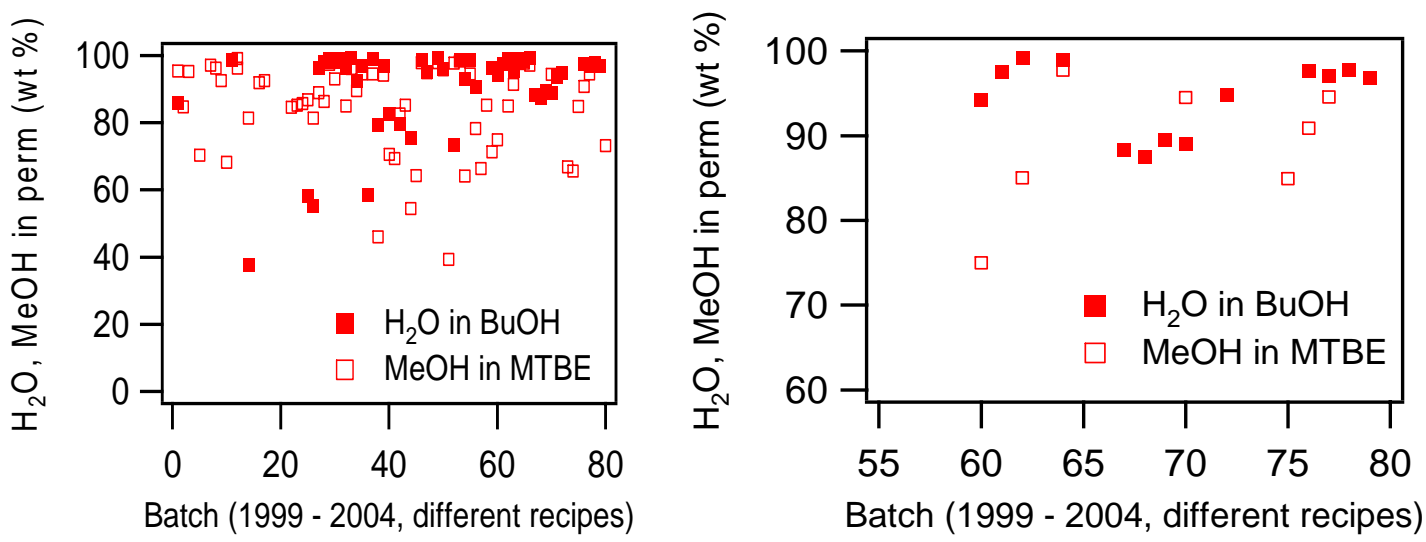

Figure 5.1 Methanol and water concentration in permeate for all membrane batches in the period 1999-2005 (left) and performance of membrane batches made on commercial supports only (right) 


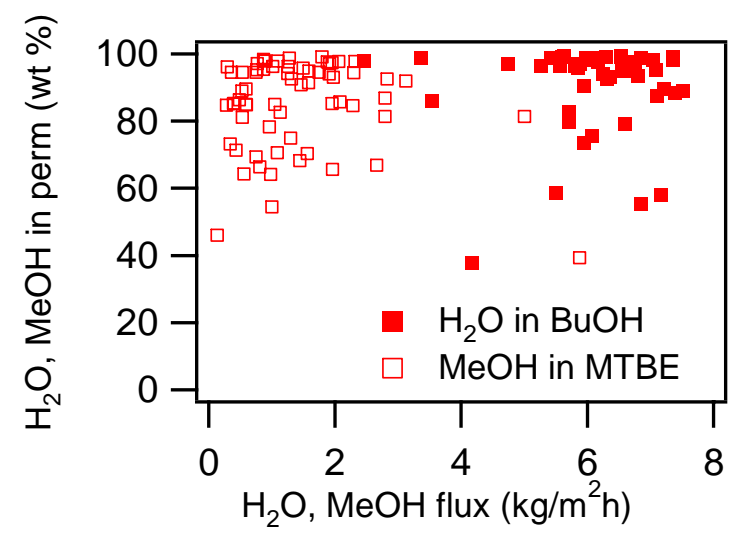

Figure 5.2 Methanol or water conc. in the permeate vs. $\mathrm{MeOH}$ or $\mathrm{H}_{2} \mathrm{O}$ flux

For the membranes made with commercial tubes the variation is much smaller, see Figure 5.2. In making the commercial-tube supported membranes we were obviously taking advantage of the intrinsic learning we had with the 'homemade' support tubes. The main advantages of the commercial supports are that they are available in large quantities, that they meet the specifications of a membrane producer, and that their price is rather low as compared with other suppliers. Finally membranes on commercial supports with a length of 1 meter have been made and 24 of these membranes have been used in testing with a $1 \mathrm{~m}^{2}$ membrane area skid-mounted unit in $\mathrm{MeOH}-\mathrm{MTBE}$ process liquid and showed very good results, see further in this chapter. The results of Figure 5.1 have been depicted in a different way in Figure 5.2. An analysis of all methylated silica membranes made so far (period 1999 till 2005) shows that the reproducibility of the selectivity of the membranes in general is good when water is separated from butanol (black squares). For the same membranes, the variation in selectivity for the separation of methanol from MTBE is somewhat larger, see Figure 5.2 (open squares). The variation in water flux is $50 \%$ : about 5 to $7.5 \mathrm{~kg} / \mathrm{m}^{2} \mathrm{~h}$. For the same membranes the variation in $\mathrm{MeOH}$ flux is a factor of 10, while the difference between the maximum and minimum fluxes for water and methanol is the same. The reason for the large variation in selectivity and flux for methanol separation can be explained by the pore size of the membrane compared to the size of the permeating molecule. A water molecule (2.6 Ångstrom in size) is smaller than methanol (appr. $3.9 \AA$ ) and therefore methanol cannot pass the very small pores present in the membrane that are only accessible to water molecules. Thus the flux of water is much larger than methanol as more pores are accessible for water (the driving force is comparable). Therefore the relative influence of (flow through) defects or somewhat larger pores that are always present in the membrane, e.g. caused by the pore size distribution, is larger for methanol in MTBE than for water in butanol. In the case of methanol in toluene, fluxes are higher than in MTBE as the driving force is higher and the fluctuation in the flow is in this case somewhat lower. This is supported by the fact that membranes with a higher flux in general have a higher selectivity, as the relative contribution of defect flow is smaller. Though the amount of defects is small, it is still difficult to absolutely control them. Variations in the fluxes between the single membrane tubes made on lab scale will, however, become an average flux number when the membranes are used in bundles of tubes in large modules. Also a 'robotized' production will rule out part of the currently observed variations.

\section{Membrane characterisation and process testing}

In Table 5.1 the performance characteristics of a methylated silica membrane applied on the commercial support tube is given for different pervaporation mixtures. In the separation of $5 \mathrm{wt} . \%$ water from butanol or $5 \mathrm{wt} . \%$ methanol from MTBE or toluene the permeate typically contains $98^{+}$wt.\% of water or methanol. The methanol flux in MTBE is much lower than in toluene as the driving force (partial pressure of methanol) is lower in the mixture with MTBE as compared to the driving force in toluene under the test conditions used. A feed containing $5 \mathrm{wt} . \% \mathrm{EtOH}$ in toluene typically leads to a permeate of $75 \mathrm{wt} . \%$ ethanol with a very low total 
flux. This indicates that only a few pores are available for ethanol transport and the nonselective contribution of defects is relatively high.

Table 5.1 Standard test mixtures and conditions

\begin{tabular}{llcccc}
\hline Mixture & Feed conc. & $\begin{array}{c}\text { Temp. Vacuum pressure } \\
\left({ }^{\circ} \mathrm{C}\right)\end{array}$ & $\begin{array}{c}\text { Total flux } \\
(\mathrm{mbar})\end{array}$ & $\begin{array}{c}\mathrm{MeOH}\left(\text { or } \mathrm{H}_{2} \mathrm{O}\right) \text { conc. } \\
\left(\mathrm{g} / \mathrm{m}^{2} \mathrm{~h}\right)\end{array}$ \\
\hline $\mathrm{MeOH} / \mathrm{MTBE}$ & 5 wt.\% $\% \mathrm{MeOH}$ & 45 & 10 & 866 & 98.4 \\
$\mathrm{MeOH} /$ toluene & 5 wt.\% $\mathrm{MeOH}$ & 65 & 10 & 4666 & 98.2 \\
$\mathrm{EtOH} /$ toluene & 5 wt.\% $\mathrm{EtOH}$ & 65 & 10 & 185 & 76.2 \\
$\mathrm{H}_{2} \mathrm{O} / \mathrm{BuOH}$ & 5 wt.\% $\mathrm{H}_{2} \mathrm{O}$ & 95 & 10 & 6928 & 98.8 \\
\hline
\end{tabular}

Following these lab scale results a pilot scale $1 \mathrm{~m}^{2}$ membrane area installation (Figure 5.3) has been used for MeOH-MTBE separation at the location of a chemical industry using their on-site available process mixture. In these tests about $0.9 \mathrm{~m}^{2}$ of membrane area and a feed amount of 900 litres containing about $24 \mathrm{wt} . \%$ methanol in MTBE has been used. Tests were performed at $95^{\circ} \mathrm{C}$. The main results of a batch test run are presented in Figure 5.4. In these experiments the aim was to reduce the feed concentration to a value lower than $1 \%$ of methanol by continuously pumping the feed liquid over the membrane. The tests were successful and the methanol concentration in this feed can be reduced to $<0.5 \mathrm{wt} . \%$. At methanol concentrations lower than about $3 \mathrm{wt} . \%$ the methanol concentration in the permeate decreases as the driving force for methanol permeation decreases significantly. The loss of MTBE is still rather small and the permeate contains more than $85 \mathrm{wt} . \% \mathrm{MeOH}$ overall after about 17 hours of testing. Furthermore, comparable to the lab scale measurements it was shown that the flux strongly increases with temperature and fluxes of more than $25 \mathrm{~kg} / \mathrm{m}^{2} \mathrm{~h}$ are obtained at $95^{\circ} \mathrm{C}$ for a feed mixture containing $25 \mathrm{wt} . \% \mathrm{MeOH}$.

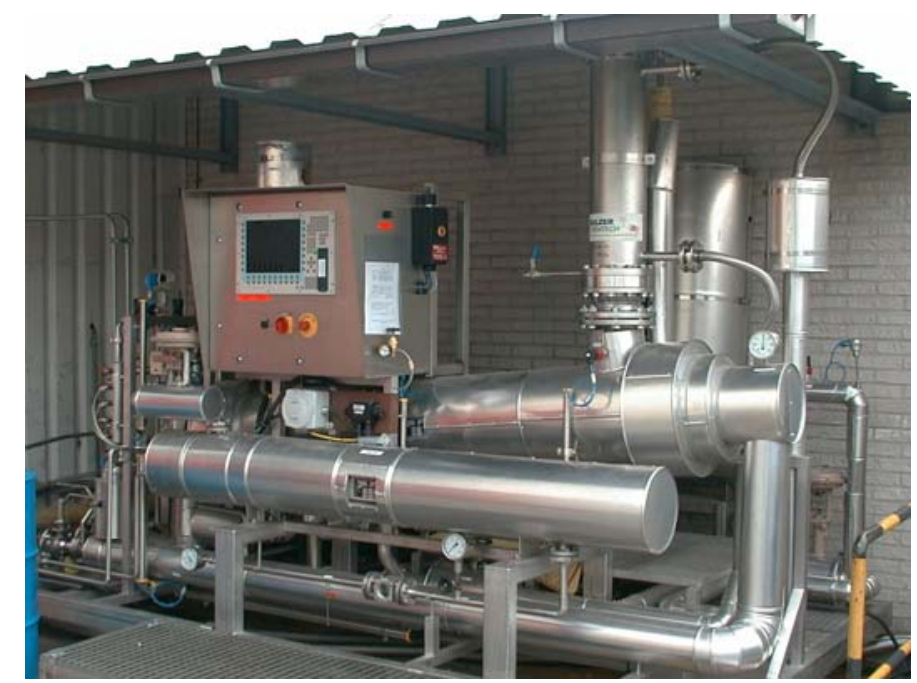

Figure 5.3 Pilot scale $1 \mathrm{~m}^{2}$ membrane area pervaporation test system 

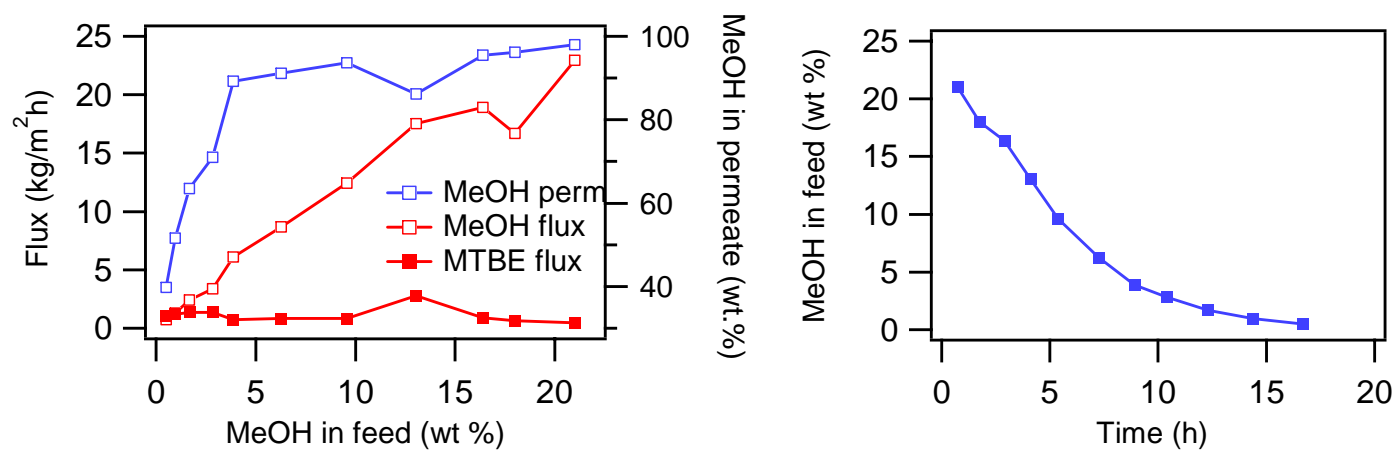

Figure 5.4 Pilot scale test results with $0.9 \mathrm{~m}^{2} \mathrm{PV}$ membrane test system at $95^{\circ} \mathrm{C}$ : left, fluxes and $\mathrm{MeOH}$ concentration in permeate vs. feed, and right, decrease of the $\mathrm{MeOH}$ concentration in the feed vs. time

\section{Pervaporation process economics}

Lab scale measurements have been performed at different temperatures and feed concentrations for a $\mathrm{MeOH}$-toluene mixture. This has been done for evaluating the possibility of using pervaporation membranes to replace an existing $\mathrm{MeOH}$-toluene separation process. In the conventional process an excess of water is used in an extraction system followed by two distillation columns, see Figure 5.5. By membrane pervaporation this could be done in one step, replacing the extraction and one or two distillation steps. In Figure 5.6 fluxes and permeate concentrations are presented for different feed concentrations of methanol in toluene at a feed temperature of $60^{\circ} \mathrm{C}$. The permeate contains almost pure $\mathrm{MeOH}$ and even for a feed containing $1 \mathrm{wt} . \%$ methanol the permeate still contains more than $97 \mathrm{wt} \% \mathrm{MeOH}$. The methanol flux first increases strongly with an increase in methanol feed concentration and at about $5 \mathrm{wt} \% \%$ in the feed it only slowly increases with the feed concentration. The reason for this is that the driving force for methanol transport is based on the activity and this hardly increases anymore above $5 \mathrm{wt} . \% \mathrm{MeOH}$. When the flux is plotted against this driving force a perfectly straight line is obtained, such graph is not given here.

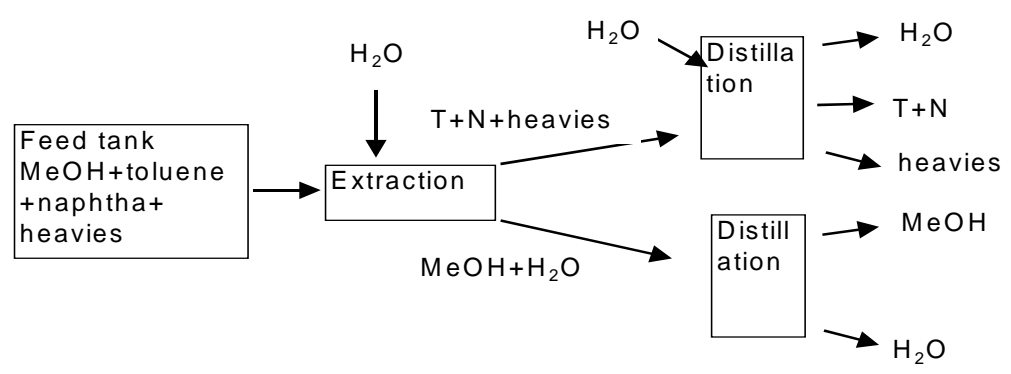

Figure 5.5 Schematic presentation of existing $\mathrm{MeOH}$-toluene process

These results have been implemented in the ASPEN+ flow-sheeting programme and for both the conventional process and the membrane based process the economics have been calculated. The economics for the pervaporation process appear to be much better than for the conventional process, see Figure 5.7. This is mainly caused by significantly lower variable operating costs as two large energy consuming distillation columns are replaced by membranes: almost $80 \%$ of the energy can be saved. 


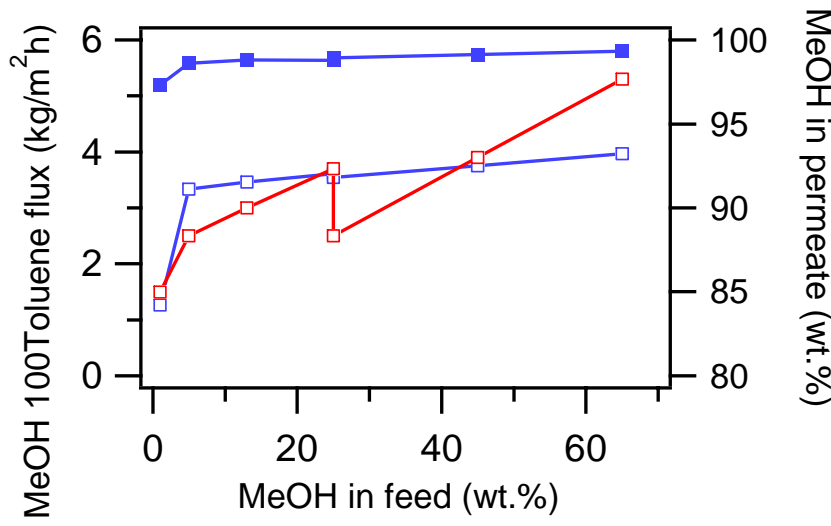

Figure 5.6 Influence of feed concentration on $\mathrm{MeOH}$ and 100'toluene flux and permeate purity for MeOH-toluene

Conclusions for silica based-pervaporation membranes

Inorganic methylated silica membranes have been developed at industrial size and they are both selective for water and methanol pervaporation in organic mixtures. Lab scale manufacturing recipes and procedures have been translated to commercially available low-cost substrates and it has been shown that these membranes have more than sufficient performance for commercial use. In pervaporation these membranes combine good selectivities with very high fluxes for the separation of methanol from organics like MTBE and toluene. These methylated silica membranes can also be used for water separation from organics. By up-scaling and repeated manufacturing the variation in performance as observed in lab-scale manufacturing is reduced strongly. However, from tube to tube some variation is still present due to small variations in the pore size distribution between tubes. These variations are not important anymore for commercial use, as an average flux will appear when the membranes are used in bundles of tubes in large modules. Pilot scale testing up to a size of $1 \mathrm{~m}^{2}$ membrane area has shown that the membrane performance is good and comparable to the lab scale results. Economic calculations have shown that these inorganic pervaporation membranes can very well replace and/or debottleneck existing processes like distillation and extraction.

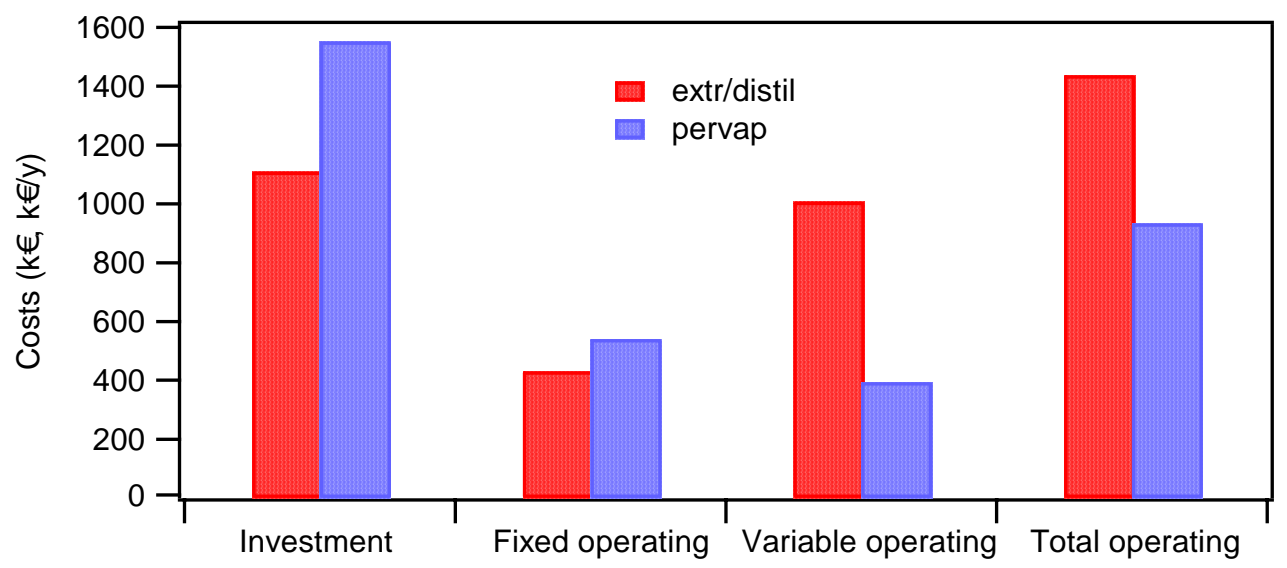

Figure 5.7 Cost comparison of conventional extraction/distillation process vs. pervaporation 


\section{Concluding remarks}

Sol-gel membranes for molecular separations promise to become an important unit operation for energy-efficient industrial separations by replacing or debottlenecking distillation columns or making new separations possible. It has been demonstrated that these membranes can be manufactured at industrial scale and at costs that are economically attractive. The sol-gel process gives infinite degrees of freedom to make membranes with tailor-made characteristics. However, this also means that many parameters in the manufacturing process have to be controlled to achieve reproducible production. The support systems of sol-gel membrane layers play a dominant role in the quality of the membranes (defects) and cost of the total membrane system. Next to the challenge of reproducible large scale manufacturing there is the issue of long term stability of these membranes at temperatures well above $100^{\circ} \mathrm{C}$ and in hydrothermal environments. Although significant steps forward have been made towards a hydrothermally stable membrane, the scientific understanding of the transformation processes in the amorphous sol-gel layers during their operation is still very limited. This research will be the key to robust microporous sol-gel membranes with a very wide and broad application range in industrial processes. Only proven long-term and high-quality performance in pilot and demonstration scale applications with a thorough understanding of the mechanisms involved will lead to general acceptance of this breakthrough technology in industry. 


\section{References}

[1] Humphrey J., L. A. F. Seibert:: Chem. Eng. Prog. 92 (1992) 32-41.

[2] M. Ulbricht: Polymer 47 (2006) 2217-2262.

[3] Y. S. Lin, I. Kumakiri, B. N. Nair, H. Alsyouri: Separ. Purif. Techn. 31 (2002) 229-379.

[4] J. Caro, M. Noack, P. Koelsch, R. Schäfer: Micropor. Mesopor. Mater. 38 (2000) 3-24.

[5] J. Caro, M. Noack, P. Koelsch: Adsorption 11 (2005) 215-227.

[6] T. Tsuru, T. Hino, M. Yoshioka, J. Asaeda: Membr. Sci. 186 (2001) 257-265.

[7] H.W. Deckman, R.R. Chance, D.M. Cox, D; W.G. de Gijnst, J.J. Reinoso: United States patent, US 2003/0005750 (2003).

[8] B. C. Bonekamp, A. van Horssen, L. A. Correia, J. F. Vente, W.G. Haije: J. Membr. Sci. 278 (2006) 349-356.

[9] C.J. Brinker, G.W. Scherer: Sol-Gel Science-The Physics and Chemistry of Sol-Gel Processing, Academic Press, New York (1990).

[10] J. Campaniello, C. W. R. Engelen, W. G. Haije, P. P . A. C. Pex, J. F. Vente: Chem. Commun (2004) 834-835.

[11]R. M. de Vos, H. Verweij: Science 279 (1998) 1710-1711.

[12] T. A. Peters, J. Fontalvo, M. A. G. Vorstman, N. E. Benes, R. A. van Dam, Z. A. E. P. Vroon, E. L. J. van Soest-Vercammen, J. T. F. Keurentjes: J. Membr. Sci. 248 (2004) 7380.

[13] R. M. de Vos, W. F. Maier, H. Verweij: J. Membr. Sci. 158 (1999) 277-288.

[14]P. Puhlfürß, A. Voigt, R. Weber, M. Morbé: J. Membr. Sci. 174 (2000) 123-133.

[15]T. van Gestel, C. Vandecasteele, A. Buekenhoudt, C. Dotremont, J. Luyten, R. Leysen, B. van de Bruggen, G. Maes: J. Membr. Sci. 207 (2002) 73-89.

[16] J. Sekulic, J. E. ten Elshof, D. H. A. Blank: Adv. Mater. 16 (2004) 1546-1550.

[17] J. Sekulic: PhD. Thesis, University of Twente (2004).

[18] T. van Gestel, H. Kruidhof, D. H. A. Blank, H. J. M. Bouwmeester: J. Membr. Sci. 284 (2006) 128-136.

[19] U. Aust, S. Benfer, M. Dietze, A. Rost, G. Tomandl: J. Membr. Sci. 281 (2006) 463-471.

[20] H. Imai, H. Morimoto, A. Tominaga, H. Hirashima: J. Sol-Gel Sci. Techn. 10 (1997) 45-54.

[21] G. I. Spijksma: PhD. Thesis, University of Twente (2006).

[22] M. Asaeda, T. Tsuru, P. Uchytil, T. Yoshioka, M. Ootani, N. Nakamura: Proceedings of the fifth Conference on Inorganic Membranes, Nagoya (1998) 322-325.

[23] M. Asaeda, M. Ishida, Y. Tasaka: Separ. Sci. Techn. 40 (2006) 239-254.

[24] J. Yang, T. Yoshioka, T. Tsuru, M. Asaeda: J. Membr. Sci. 284 (2006) 205-213.

[25] M. Asaeda, M. Kanezashi, T. Yoshioka, T. Tsuru: Mater. Res. Soc. Symp. Proc. 752 (2003) 213-218.

[26] H. L. Castricum, A. Sah, R. Kreiter, D. H. A. Blank, J. F. Vente, J. E. ten Elshof: to be published (2007).

[27] M. C. Duke, J. C. D. da Costa, G. Q. Lu, M. Petch, P. Gray: J. Membr. Sci. 241 (2004) 325333.

[28] M. C. Duke, J. C. Diniz da Costa, D. D. Do, P. G. Gray, G. Q. Lu: Adv. Funct. Mater. 16 (2006) 1215-1220.

[29] R. W. van Gemert, F. P. Cuperus: J. Membr. Sci. 105 (1995) 287-291.

[30] J. Sekulic, M. W. J. Luyten, J. E. ten Elshof, N. E. Benes, K. Keizer: Desalination 148 (2002) 19-23.

[31]B. Bettens, S. Dekeyzer, B. van der Bruggen, J. Degreve, C. Vandecasteele: J. Phys. Chem. 109 (2005) 5216-5222.

[32] C. Casado, A. Urtiaga, D. Gorri, I. Ortiz: Separ. Purif. Techn. 42 (2005) 39-45.

[33] S. Sommer, T. Melin: Chem. Eng. Process. 44 (2005) 1138-1156.

[34] A. Jonquieres, R. Clement, P. Lochon, J. Neel, M. Dresch, B. Chretien: J. Membr. Sci. 206 (2002) 87-117. 